\title{
Psychometric properties of a newly developed learning difficulties scale in the Omani society
}

\section{Ibrahim A. Al-Qaryout ${ }^{1}$, Maher M. Abu-Hilal ${ }^{2}$, Humaira Alsulaimani ${ }^{2}$}

${ }^{1}$ Early Childhood Department, Sultan Qaboos University, Oman

${ }^{2}$ Psychology Department, Sultan Qaboos University, Oman

\section{Oman}

Correspondence: Ibrahim Al-Qaryouti, P.O. Box 32 Alkhoudh123 Muscat, Oman.

E-mail: ibrahimq@squ.edu.om

(c) Education \& Psychology I+D+i and Editorial EOS (Spain) 


\section{Abstract}

Introduction. Learning difficulties (LD) is a recent construct. It has been agreed that the individual who suffers from learning difficulty has a disorder in one or more of the basic psychological processes, including attention, cognition, formation of concepts, memory, problem solving, understanding or reading, speaking or writing, or computing.

Method. This study was designed to test the construct (convergent and discriminate) validity of this conception of LD with exploratory factor analysis (EFA) and confirmatory factor analysis (CFA). Also, responses of normal students were compared to responses of students identified as having learning difficulty. The sample comprised 410 children from Muscat School Zone, who were rated by their teachers (30) teachers based on the newly questionnaire. The questionnaire is composed by six domains and each measures one component of difficulties. These components are difficulties in: perception, attention, memory, writing, arithmetic and reading.

Results. Reliability analysis and factor analysis revealed that the measure possesses both reliability and factorial validity.

Discussion and conclusion. The CFA confirmed the structure of the measure. ANOVA revealed significant differences between normal and LD children on most of the LD components, the providing further support to its construct validity.

Key words: Learning difficulties, psychometric, factor analysis, Oman. 


\title{
Propiedades psicométricas de una escala de nueva elabo- ración sobre dificultades de aprendizaje, en la sociedad omaní
}

\begin{abstract}
Resumen
Introducción. El término dificultades de aprendizaje (DA) es una construcción reciente. Se ha acordado que el individuo que sufre de dificultades de aprendizaje tiene un desorden en uno o más de los procesos psicológicos básicos, como la atención, la cognición, la formación de conceptos, memoria, resolución de problemas, entender problemas, leer, hablar,escribir, o aprender informática

Método. Este estudio fue diseñado para probar la validez de constructo (convergente y discriminante) de esta concepción deDA con el análisis factorial exploratorio (AFE) y confirmatorio (AFC). Además, las respuestas de los estudiantes normales se compararon con las respuestas de los estudiantes identificados con dificultades de aprendizaje. La muestra estuvo formada por 410 niños esc olares de la zona de Muscat, que fueron calificados por sus profesores (30) maestros, basándose en el cuestionario de nuevo. El cuestionario está compuesto por seis dominios y cada uno mide un componente de dificultades. Estos componentes son : dificultades en la percepción, atención, memoria , escritura, aritmética y lectura.
\end{abstract}

Resultados. Análisis de fiabilidad y análisis factorial revelaron que la medida tiene tanto fiabilidad y validez factorial.

Discusión y conclusiones. El AFC confirmó la estructura de la medida. Los ANOVA revelaron diferencias significativas entre niños normales y DA sobre la mayor parte de los componentes, prestando gran mayor apoyo a su validez de constructo.

Palabras clave: Dificultades de aprendizaje, análisis psicométrico, análisis factorial. 


\section{Introduction}

Learning difficulties as an educational construct has been introduced recently to the field of special education. It has developed as a result of the efforts made by researchers in the field of education, psychology, medicine and neurology. It does not only affect the individual in his/her childhood stage, but its effects extend to all stages of life.

Researchers (e.g., Hallahan, Lioyed, Kauffman, Weiss, \& Martinez, 2005; Smith, 2007; Wong, 2004) agree that the one who suffers from learning difficulties is an individual with disorder in one or more of the basic psychological processes including attention, cognition, formation of concepts, memory, problem solving, understanding or using of language either spoken or written. Therefore, the impact of disorder occurs in the ability to read and write or listen and to make mathematical tasks. This construct does not include learning problems due to sensory, motor, or mental disabilities nor even emotional disturbances or lack of environmental, cultural or economic problems.

Because learning difficulties has many definitions and different diagnostic practices; there is a clear problem in estimating the prevalence of this phenomenon among students. According to Hallahan et al. (2005), the percentage of prevalence of learning difficulties in the American society, is estimated between 2\% - 9\%. AL Zarrad (1991) pointed out that the prevalence of learning difficulties in the United Arab Emirates (UAE) society is estimated at 13.7. This has been confirmed also by AL Baili, Alnshwati, Mahmoud, \&Alshayeb (1991), by noting that the prevalence of this phenomenon in the UAE is about 12.79\%. Tawfiq (1993) showed that the percentage of pupils with learning difficulties in the Sultanate of Oman is about $10.8 \%$ whereas it ranged between 16.5\% - 26\% in Egypt (AL-Zayat, 1998). In Qatar it's estimated at about 9\% (Almannai, 2000).

The differences in the prevalence of learning difficulties can be attributed to the nature of accredited benchmarks used, the environmental context, and social and economic situation besides the quality of precautionary services that are offered to the families and schools (Hallahan, et.al, 2005). The researchers (e.g. Alqabali, 2204; AL-Zyat, 1998; Putrus, 2009; Wong, 2004) argue that learning difficulties is associated with two major factors: Developmental difficulties, including primary developmental disorder such as memory, attention, and cognition, and secondary that include thinking, speech and language; and academic difficulties. 
The American Educational Office refers to seven specific areas displayed by people affected with learning difficulties. They are: oral expression, written expression, understanding what they hear, basic reading skills, reading comprehension, calculation, and mathematical logic. Some researchers interpret learning difficulties according to the severity of difficulty: mild, moderate, or severe. On the other hand, Yale University adopted and pointed out three modes of reading difficulties. The first focuses on the phonological awareness difficulties; the second focuses on the phonological difficulties with short term memory; and the third focuses on the general cognitive weakness (Schulter, Conners \& Osborne, 1991; Wong, 2004; Batshow, 2002). Next, we provide explanation for the field that characterizes the individuals with learning difficulties:

\section{Attention}

The problem basically includes hyperactivity, lack of focus, and lack of the spatial directionality. The hastiness appears with these students besides the tendency to respond hastily, and do an immediate reaction without thinking about consequences. The individuals with learning difficulties fail in selecting important stimulants and ignoring the non important. They also suffer from the problem of not being able to transfer attention one educational situation to another and the difficulty of following up the skills in sequence (Aldhaher, 2004; Batshow, 2002; Heward, 2006).

\section{Perception}

The perception disturbances among students with learning difficulties are not clear due to the relationship between attention, thinking, and language abilities. The perception works in organizing, building and explaining various stimuli. The individuals who suffer from learning difficulties often have difficulty in the interpretation of the meaning of stimuli in the environment because of poor cognitive performance. In some students, it's observable that they have difficulty in physical activities including motor skills. Some students are described that they are ten thumbs or two left feet, and these difficulties include the deficit in the fine and gross motor skills. (Hallahan, et.al, 2005) The problems of perception verify by including visual, auditory, or tactile motor cognition. Individuals with the problem of visual perception have difficulty in transcription, while the individuals with the problem of auditory perception might face a problem in distinguishing sounds and blinder them (Salim, Alshahat, \& Ashour, 2003). 
Several studies indicated that children affected with learning difficulties suffer from perception auditory difficulties besides the language and phonology difficulties (Lyon, 1995; Stahl \& Murray, 1994; Ball \& Blachman, 1991). AL-Qaryouti (2010) referred that the students affected with learning difficulties have weakness of the audio-visual discrimination compared to students without disabilities.

\section{Memory}

Memory is the most important and basic attribute of the individual and it enables $\mathrm{him} / \mathrm{her}$ to receive the stimuli around him/her; to obtain information, and to be able to process, encode, and receive information, store and use it in the future (Sulaiman, 2003). Many contemporary scholars of memory agree that the factors that affect remembering, retention, and retrieval are the same that affect the achievement and acquisition of information. Also, the conditions that facilitate learning are the same that facilitate retention. The level of retention and retrieval are the same levels of learning from the point view of the cognition theory (Albatayneh, Aarashdan, Alsabaylh, \& Alkhatatbah, 2009; Togeson, 1988).

The audio and visual memory is directly connected with the weakness in reading and calculation. The residue of information in working memory is fundamental and this has been confirmed by many studies. These studies have shown that individuals with learning disabilities suffer from problems in working memory (Logie, Gillhooly \& Wynn, 1994; Geary, Hoard, Craven \& Desoto, 2004; Vander, Vander \& De Jung, 2005; Mabbott \& Bisanz, 2008; Swanson, Cochran \& Evers, 1989; Swanson, 1987; Geary, Hoard, Craven, Nugent \& Numtee, 2007).

\section{Reading}

The academic achievement of students with learning difficulties is significantly less than that of non-disabled peers who are equal in chronological age, mental development, and experience in school. This occurs clearly in reading, whether in reading comprehension, or in decoding symbols. They also have difficulty in retaining the reading area; they may delete words or insert weird words in text and reverse some words, with week fluency and errors in pronunciation. Also students with learning difficulties tend to replace one word with another. They also have difficulty in distinguishing between the similar - shape letters but with various pronunciations. They have weakness in distinguishing between the similar pronunciation letters but with different drawing. They also read fast but not clearly or read slowly. 
It is worth noting that some students suffer from the disorder in both receptive and expressive language. Others have difficulty in one type of receptive or expressive language types (Salem, EI-Shahat, Ashour, 2003; Al-Waqfi, 2003; Jarrar 2007; Puller, 2002). Students, who have difficulty in decoding invariably, have problems in fluency. Reading fluency is considered as the main reason for reading comprehension (Werts, Gulatta \& Tompkins, 2007; Plaza \& Gultton 1997)

\section{Writing}

The writing skills are connected with the listening, speaking, and reading skills. If the student encounters difficulties in these three skills, he/ she will often face difficulty in learning the components of writing. Many of the students affected with learning difficulties have problems in handwriting, spelling and expression when compared to their peers without disabilities. Students with learning difficulties show less performance compared to their nondisabled peers in most of expressive writing tasks (e.g vocabulary, grammar, spelling, and punctuation). The writing of learning difficulties students lack organization and sequence on one line, they never leave the appropriate spaces between words; and they do not write words with in equal size. Sometimes the writing is in capital letters and sometimes in small letter. They also replace a letter with another, reserve letters, and sometimes mix them.

When comparing the written language of individuals with learning difficulties with their peers without difficulties, it is observed that the formers use complex sentences less than the latter do. Learning difficulties students Include fewer type of words and write paragraphs that are less well (Batshow, 2002).

\section{Math}

Students with learning difficulties are usually known by have a disorder, or deficiency in processing knowledge is due to the difficulties in attention and storage during solving mathematical tasks or ignoring some of the mathematical steps. They also have difficulty in solving mathematical problems whether basic or fractures. They also have difficulty in distinguishing numbers and understanding relationships and trends when solving mathematical problems. These students also have difficulty in calculating orally counting within a series of numbers $(2,4,6)$ (Cowley, Parmer, Van \& Miller, 1998; Geary, 2004) 


\section{Negative Attribution}

Students affected with learning difficulties suffer from the negative attribution: a personal interpretation of the reasons of success or failure. Due to the repeated academic failure, students' motivation deteriorates and they become more convinced that they will not be able to succeed and succumb to failure. They don't exert effort as this acquired deficit is the result of poor performance. Consequently, they become dependent on others (smith, 2007)

\section{Weakness of social and behavioral skills}

Approximately $75 \%$ of students with learning difficulties suffer from social problems which have a negative impact on their perception of themselves and their ability to establish relationships with others. Difficulty in language and academic failure are behind such problems (Batshow, 2007; Smith, 2007). Heward (2006) referred to Kavale \& Formess, (1996) which included a review of 152 research articles summarized that $75 \%$ of student affected with learning difficulties show a deficit in social skills. Because of their poor social skills, they are refused. They also find difficulty in making friends and tend to be introverted and isolated. Students with learning difficulties are sometimes overactive. However, some students lack activity and they act rashly and impetuosly. They also misjudge the behaviors' and feelings of others (Schulte, canners \& Osborne, 1999; Ceary, 2004; AI- Waqfi, 2003) According to Cullinan (2002), 15\% of students who are affected with learning difficulties in Indiana suffer from behavioral problems.

The theorists of cognitive theory confirm that effective learning depends on the learner's ability to accurately interpret stimuli and to give them meaning. These scholars attribute the process of explaining and exploring of environmental expertise to three main factors: attention, including the ability to test environmental dimensions; cognition, including exploring, analyzing information and know and figure out meanings; and memory, including organizing meanings in a way that will allow remembering and retrieving when needed. These three cognitive processes in addition to thinking and language abilities, are the most important foundations of mental activity knowledge of the individual, which is the foundation upon which academic achievement depend (Al-Zayat, 1998 Kirk \& Chalfant, 1984; Kirk, 1987) Thus, any defect or weakness in one or more of the three operations necessarily lead to many academic difficulties. So, it can be reported that the developmental learning disabilities are the precursors of later academic learning difficulties. 
Aims

The purpose of the study was to test the contract validity of the scale of learning difficulties among Omani students. Also, we wanted to test if the structure is different across the two populations: normal students and students with learning difficulties. The invariance that would allow us to compare different population as of this average performance on the scale and it is dimensions.

\section{Method}

\section{Participants}

The sample of this study consisted of 410 students in grade 3 ( $n=213$ : boys=111, girls $=102)$ and grade $4(n=190$ boys=102, girls=88) with 7 missing cases. Normal students were 215 (boys $=103$, girls=112), while students with learning difficulty were 186 (boys=108, girls=78). The basis for selecting subjects was schools which students with learning difficulties attend. Normal students were randomly selected from these schools. Research assistants were instructed to select the highest two students and the lowest two students in achievement from each section in the schools.

\section{Instruments}

The researchers designed an instrument that purports to measure learning difficulties as rated by teachers in six domains. A pool of items $(n=124)$ was developed. The instrument was piloted after a group of referees attested its face validity. As a result of piloting only 62 items were retained. The items were distributed over the domains as shown in Table 1. The rating was anchored by 4-point scale from not at all (1) to frequently (4).

Table 1. Domains of Disability, Number of Items and their Cronbach Alpha by Type (Normal vs., Learning Difficulty)

\begin{tabular}{llccc}
\hline Ser & Domain & Number of & \multicolumn{2}{c}{ Alpha } \\
\cline { 4 - 5 } & & & Normal & L D \\
\hline 1 & Perception & 10 & .83 & .73 \\
2 & Attention & 10 & .81 & .83 \\
3 & Memory & 10 & .83 & .77 \\
4 & Writing & 10 & .83 & .84 \\
5 & Math & 10 & .87 & .68 \\
6 & Reading & 12 & .91 & .90 \\
\hline
\end{tabular}




\section{Procedure}

A group of teachers in the schools at which students with learning difficulties attended were trained to administer the instrument during a full day workshop. The instrument was introduced and explained to the selected teachers. The domains of the instrument were explained and the items belonging to each domain were also explained. Teachers were observed as they tried the tool on students from outside the sample.

As for normal students, the class teachers attended the same workshop and tried the instrument on three students each to make sure they know what is expected of them. There was a discussion with the 30 teachers who volunteered to administer the instrument. The data collection lasted about two months. Also, teachers were instructed to register the students' scores in Arabic Language and mathematic.

\section{Data analysis}

Data was analyzed by confirmatory factor analysis with AMOS 16. Reliability was performed for each of the extracted factors with SPSS 16.

\section{Results}

The purpose of the study was to confirm the structure of the instrument by way of confirmatory factor analysis (CFA). Also, we intended to test if the structure is invariant across the two populations (Normal and learning difficulty). Several indexes of goodness of fit were used to evaluate the model. We specified seven factors representing the six domains and the seven the factor for achievement in math and Arabic. The model assumed a correlated factors model. Also, parcels were used instead of items. Some parcels were sum of two items and some were sum of three items. Therefore the domains (perception, attention, memory and writing) were measured by four parcels and the domains (Reading and math) were measured by five parcels. Achievement was measured by two observed scores: Arabic and math.

Since chi square is affected by sample size other indexes have been used. Comparative fit index (from 0 to 1 ) with value greater than .90 indicates acceptable fit. Also, root mean square error of approximation (RMSEA) value less than.08 indicates an acceptable fit. The analysis revealed a reasonably good fitting model $\left(\chi^{2}{ }_{(322)}=1130.87, C F I=.902, R M S E A=\right.$ .078). All loadings were significant ranging from .40 to $.96(\mathrm{Mdn}=.77)$ the factor loadings and factor correlations are presented in Figure 1. Factor correlations ranged between .84 and. 90 . 
As an evidence of construct validity the achievement factor was significantly negatively correlated with each of the six domains (rang from -.84 to -.58 ).

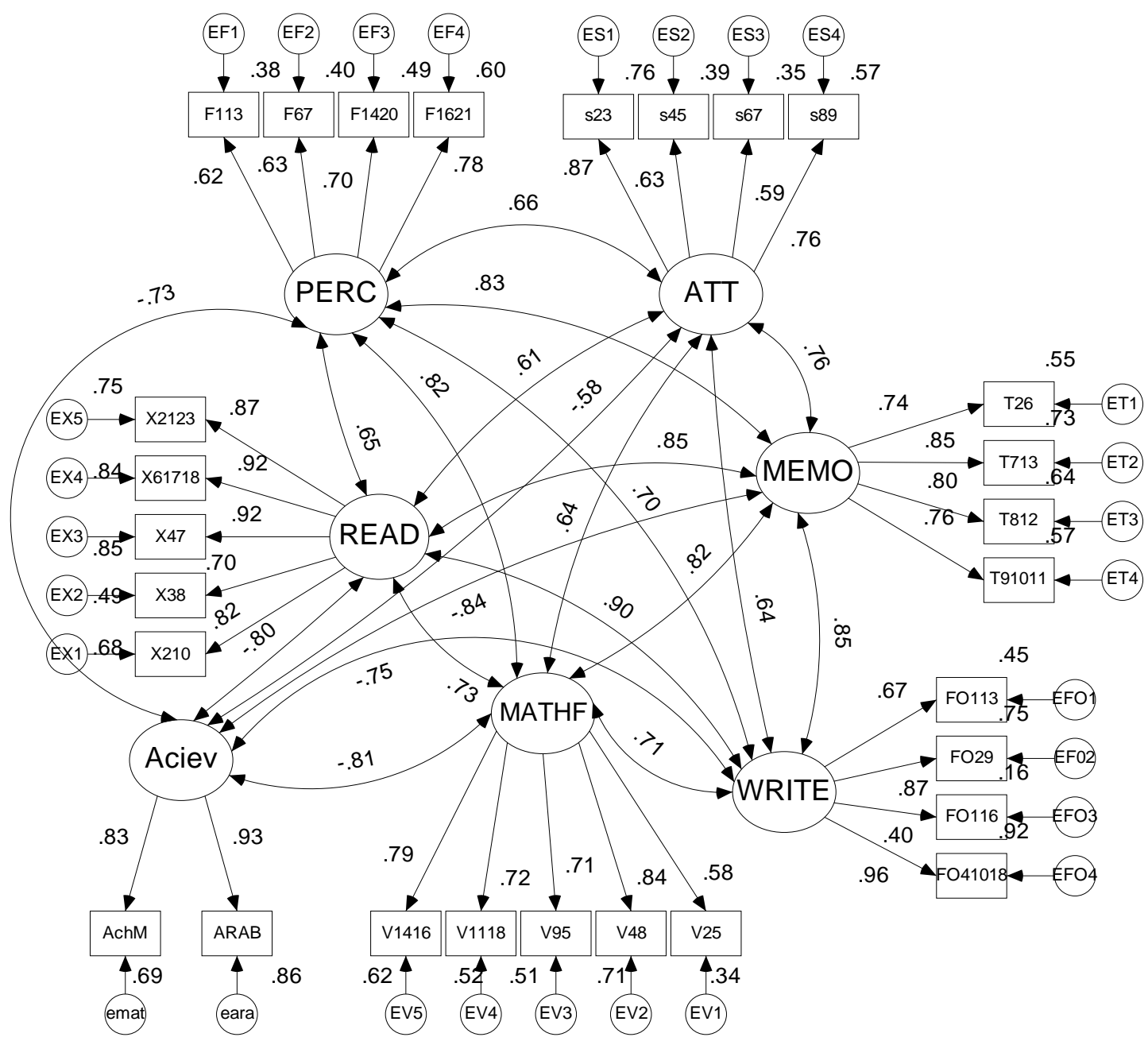

Figure 1. Factor Structure of the LD Omani Scale with Loadings and Factor Correlations

\section{Invariance across type}

A multi sample confirmatory factor analysis (CFA) was conducted on the ratings of normal students vs. Students with learning disability. The model was not of a good fit $\left(\chi^{2}{ }_{(568)}\right.$ $=1321.84, C F I=.87 ; R M S E A=.057)$ when no constraints of equality were assumed. Equality constraints were then assumed on factor loadings. The results showed that the model with factor loadings invariance was marginally $\operatorname{good}\left(\chi^{2}{ }_{(588)}=1454.19 C F I=.86, R M S E A=.06\right)$. The chi square and CFI indicate a poor fit however, RMSEA indicates a good fit. The other constraints of equality across the two types (normal vs. Learning disability) revealed that intercepts, structural covariances and measurement residuals are not invariant (equal). 


\section{Discussion}

We addressed issues regarding the criteria used to classify children as having learning difficulties. The range and nature of associated dificits in writing, reading and mathimatics tasks, as well as the potential memory, attention and perception. The definition of LD concerns whether the memory, perception and attention will affect the three Rs (reading, writing and arethmatic). Also, we discussed the weaknesses of social and behavioral skills and their effects on academic achievement. Therefore, the purpose of this study was to develop a measure that can tap this understanding of learning difficulty. This instrument is of great importance to the Omani society. The results revealed that the instrument is reliable for each of the two groups. This justifies its use for research purpose. As for validity, the loadings of the parcels on their respective factors were rather high, thus, they assume validity of the parcels in measuring the factor and factorial validity has been established.

The results of the current study disagree, however, with Al-Sartawy (1995) in which he extracted only one factor via exploratory factor analysis (EFA). Due to the limitations of the EFA in which researchers can't test models, Al- Sartawy concluded erroneously one factor. Previous research indicated that learning difficulties is a multi dimensional construct. The present study confirmed our hypothesis that learning difficulties is a multi dimensional construct. Also, comparison across populations (gender, type of difficulty) can be justified based on the result that factor loadings are invariant across normal and learning difficulties students. As most previous research indicated (e.g., Al-Qaryouti, 2010; Werts, Gulatta \& Tompkins, 2007; Plaza \& Gultton, 1997) learning difficulties are strongly related to academic achievement. This study confirmed that all of the learning difficulties domains were strongly and negatively correlated with academic achievement. The results of the current study agree with Al-Qaryouti, 2010; Togeson, 1988; Lyon, 1995; Geary, Hoard, Craven \& Desoto, 2004 that learning difficulties and academic achievement are negatively correlated.

\section{Implications}

Because perception and memory were more strongly correlated with reading, writing and mathematics than with attention, it reasonable to suggest that in order to improve reading, writing and mathematics programs ought to focuses on perception and memory especially at the early intervention stage. The programs may include visual perception, auditory perception as well as long term and short term memory. 


\section{Limitations and the future research}

This study is not without limitations. It is important to note that we relied on the classification of the schools for the students as having learning difficulties. Also, it should be noted that there was lack of information about stdudents' reading achievements. Therfore, more research needs to be conducted to valídate the instrument in the Omani society. The study proposes that future research should include children with learning difficulties who are gifted and students who have attention deficit and hyperactivity (ADHD) to further validate the learning difficulties scale within Oman as well as outside Oman. A diagnostic criteria ought to be developed as a battery of tests with a broad range of skills and knowledge including at least IQ testing, working memory and behavior adaptive scale.

\section{References}

Al-Sartawy, A. (1995). Construction of screening tool for learning disabled children. The Journal of Fuclty of Education, UAEU, 2, 57-77.

Alqabali, Y. (2004). Introduction to learning disability. Amman: Dar Altareeq.

Al-Waqfi, R. (2003). Learning disability. Amman Princes Tharwait college publishing.

Aldhaher, Q. (2004). Learning disability. Amman: Dar wael.

Al bataynah, Q., Alrshdan, M., Alsabaylah, O., \&.Alkhatatbah, A. (2009). Learning disability. Amman: Dar Al maseara.

AL- Baili, M., Alnashwati, A., Mahmoud, N., \& Alshayib, A. (1991). Learning disability in normal school at U.A.E. UAEU. Journal college of Education, 7, 77-125.

Almannai, N., (2000). Learning disability Programs in Qatar. The Regan Symposium in learning disability. Amman.

AL- Qaryouti, I. (2010). Differences between normal and learning disabled students in auditory and visual discrimination at the first stage in Muscat schools. University of Bahrain. Journal of Educational and Psychological Sciences, 11, 13-37.

Al- Zayat, F. (1998). Learning Disability. Egypt: Publishing house for university.

Al -Zarad, F. (1991). Learning disability among elementally stage at UAE schools. UAE. Journal of AL Khalij, 37,121-178.

Batshow, M. (2002). Children With disabilities. Paltimore: Paul H.Brookes Publishing Com Inc. 
Ball, E., \& Blachman, B. (1991). Does phoneme awareness training in Kindergarten make difference in early word recognition and spelling? Reading Research Quarterly, 26, 49-76.

Butrus, B. (2009). Teaching students with learning disability. Amman: Dar Almasira.

Cullinan, D. (2002). Students with emotional and behavioral disorders: An introduction for teachers and other helping professionals. Upper Saddle River: Merriu Prentice Hall.

Cowley, J.Parmer, R., Van, W., \& Miller, J. (1998). Arithmetic Computation performance of students with Learning disabilities: implication for the curriculum. Learning Disabilities Research and Practice, 13, 68-74.

Geary, C. (2004). Mathematics and Learning disabilities. Journal of Learning Disabilities, 37 , 4-16.

Geary, D., Hoard, M., Craven, J., Nugent, L., \& Numtee. (2007). Cognitive mechanisms underlying achievement deficit in children with mathematical Learning disabilities. Child Development, 78(4), 1343-1359.

Geary, D., Hoard, M., Craven, J., \& Desto, M. (2004). Strategy choices in simple and complex addition: contributions of working memory and counting knowledge for children with mathematical disability. Journal of Experimental child Psychology, 88, 121-151.

Heward, W. (2006). Exceptional children: An introduction to special education. Englewood Cliff, NJ: Person Prentice Hall.

Hallahan, D., Lioyd, J., Kauffman, J., Weiss, M., \& Martinez, E. (2005). Learning disabilities: Foundation, characteristics and effective teaching. Boston: Pearson Education, lnc.

Jarrar, A. (2007). Learning disability. U.A.E. ALflah library.

Kirk, S. (1987). Learning disabled person child. Teaching Exceptional Children, 19, 2, 78-80.

Kirk, S., \& Chalfant, J. (1984). Development and academic Learning disabilities. Denver: Love Publishing.

Lyon, G. (1995). Toword adefinition of dyslexia. Annals of Dyslexia, 45, 13-30.

Logie, R., Cillhooly, K., \& Wynn, V. (1994). Counting on working memory in arithmetic problem solving. Memory and Cognition, 22, 395-410.

Mabbott, D., \& Bisanz, J. (2008). Computational skills working memory and conceptual knowledge in older children with mathematics Learning disabilities. Journal of Learning Disabilities. 41(1), 15-28. 
Plaza, M., \& Gultton, C. (1997). Working memory limitation phonological deficit, Sequential disorder and syntactic impairment in a child with a severe developmental dyslexia. Dyslexia, 3, 93-108.

Puller, P. (2002). Expert connection: Phonological awareness teaching LD. Org. Retrieved from http:// Teaching LD. Org/expert: connection/phonological.

Stahl, S., \& Murray, B. (1994). Defining phonological awareness and its relationship to early reading. Journal of Educational psychology, 86, 221-234.

Sulaiman, A. (2003). Learning disability. Egypt: Dar Al Feker Alarabi.

Schulte, A., Connors, C., \& Osborne, S. (1999). Linkages between deficit disorders and reading disability. In D.D. Duane (Ed) Reading and attention disorders: Neurobiological correlates (pp. 161-184). Timonium MD: York Press.

Smith, D. (2007). Introduction to special education making a difference. Merrill: Person Education. Inc.

Salem, M., Alshahat, M., \& Ashour, A. (2003). Learning disability. Amman: Dar Alfeker.

Sobornie, J., \& Kauffman, J. (1986). Social acceptance of learning disabled adolescents. Learning Disabilities Quarterly, 9, 55-60.

Swanson, H. (1987). Information processing theory and learning disabilities. Journal of learning Disabilities, 20, 3-7.

Swanson, H., Cochran, K., \& Evers, C. (1989). Working memory and reading disabilities. Journal of Abnormal Child Psychology, 17, 745-756.

Tawfiq, A. (1993). Learning disability among elementally stage at Oman. AL Zaqazik University. Journal of college of Education, 20(1), 22-50.

Togeson, J. (1988). Studies of children with learning disabilities, who perform poorly on memory span task. Journal of Learning Disabilities, 21, 605-612.

Wong, B. (2004). Learning about learning disabilities. California: Elsevier Academic press.

Werts, M. Gulatt, R., \& Tompkins, L. (2007). Foundation of special education: What every teacher needs to know? Person Merrill prentice Hall.

Vander S. Vander, A., \& De Joung, P. (2005). Working memory in Dutch children with learning- and arithmetic I related LD. Journal of Learning Disabilities, 38, 207-221. 
Al-Qaryouti, I. et al.

[This page intentionally left blank] 